\title{
Cluster Analysis of Unhealthy Lifestyles among Elderly Adults with Prediabetes: A Cross- Sectional Study in Rural China
}

\author{
Xiaofen Wang $\cdot$ Hailiang Gao $\cdot$ Huilan Xu
}

Received: June 14, 2019 / Published online: August 13, 2019

(C) The Author(s) 2019

\section{ABSTRACT}

Introduction: To explore the clustering and influencing factors of unhealthy lifestyles among elderly adults with prediabetes in rural China.

Methods: A cross-sectional study was conducted in Yiyang, Hunan Province, China. Through multistage cluster random sampling and an oral glucose tolerance test, we screened 461 elderly adults aged 60 years and older with prediabetes out of 2144 elderly adults who were sampled. The prediabetic adults completed a survey examining four common lifestyle factors: diet, exercise, smoking, alcohol use and the ability to acquire diabetes-related

Enhanced Digital Features To view enhanced digital features for this article go to https://doi.org/10.6084/ m9.figshare.9081341.

Electronic supplementary material The online version of this article (https://doi.org/10.1007/s13300019-00676-1) contains supplementary material, which is available to authorized users.

X. Wang $\cdot$ H. Xu $(\bowtie)$

Department of Social Medicine and Health

Management, Xiangya School of Public Health,

Central South University, Changsha, Hunan, China

e-mail: xhl1120131@163.com

H. Gao

Department of Human Resources, The Second

Xiangya Hospital of Central South University,

Changsha, Hunan, China knowledge and thereby promote one's own health-diabetes health literacy. The influencing factors were analyzed retrospectively with the Kruskal-Wallis test and ordinal logistic regression.

Results: A total of 425 elderly adults completed the survey, of whom 325 were identified with unhealthy lifestyle clustering. The KruskalWallis test showed significant differences between unhealthy lifestyle clusters by age, gender, marital status, occupation and hyperlipidemia $(P<0.05)$. Ordinal logistic regression showed that female gender $(\mathrm{OR}=0.23,95 \% \mathrm{CI}$ : 0.150 .37 ), personal annual income $\geq 2800$ $\mathrm{CNY}(\mathrm{OR}=0.61,95 \% \mathrm{CI}: 0.380 .99)$ and occupation as a worker $(\mathrm{OR}=0.56,95 \% \mathrm{CI}: 0.34$ 0.92 ) were protective factors against unhealthy lifestyle clustering. An unsatisfactory marital status (OR $=1.60,95 \% \mathrm{CI}: 1.022 .51)$ and low diabetes health literacy $(\mathrm{OR}=3.17,95 \% \mathrm{CI}$ : 1.03 9.81) were risk factors.

Conclusion: In total, $76.47 \%$ of the prediabetic elderly adults in rural China showed unhealthy lifestyle clusters. Being male and having an unsatisfactory marital status, a low personal annual income, an occupation as a farmer and low diabetes health literacy were the main risk factors for unhealthy lifestyle clustering. More effective interventions should be implemented based on these risk factors to prevent diabetes in rural elderly adults. 
Keywords: Clustering; Elders; Prediabetes; Unhealthy lifestyle

\section{INTRODUCTION}

Prediabetes is an intermediate state in which blood glucose is above normal but does not meet the clinical diagnostic criteria for diabetes. This state includes impaired fasting glucose (IFG), impaired glucose tolerance (IGT) or both conditions [1]. The prevalence of diabetes worldwide is alarming. In the US in 2012, 86 million adults had prediabetes, and approximately three times as many individuals had diabetes [2]. In China, in 2008, 148.2 million adults were diagnosed with prediabetes, and the prevalence was approximately $15.5 \%$ [3]. In 2015, the International Diabetes Federation estimated that the global prevalence of prediabetes was 318 million, and this number is expected to reach 642 million by 2040 [4]. Studies have confirmed that prediabetes can not only develop into diabetes but is also an independent risk factor for a series of diseases, including endothelial dysfunction [5], atherosclerosis [6] and myocardial infarctions [7]. In addition, prediabetes has been found to increase the risk of hospitalization and longterm mortality in hospitalized patients [8].

Unhealthy lifestyle is a pattern of behavior that increases the risk of diabetes and personal injury. Unhealthy lifestyle clustering refers to a situation in which an individual engages in one or more risky behaviors. These behaviors mainly include irregular eating, smoking, alcohol use and physical inactivity, and they may contribute to the development of prediabetes individually or in clusters. Epidemiologic evidence has shown that prediabetes is a reversible process, and early lifestyle intervention can effectively reduce the incidence of type 2 diabetes [9]. A study by Christenson et al. involving 2020 participants confirmed that a strict low-energy diet program restored blood glucose to normal for $35 \%$ of participants [10]. Dejesus et al. reported that regular aerobic exercise and a healthy diet could significantly reduce the incidence of diabetes and improve patient selfefficacy [11]. After a 9-month lifestyle intervention with 120 prediabetic participants, Stefan et al. found that $31 \%$ of the high-risk phenotype participants and $67 \%$ of the low-risk phenotype participants returned to normal glucose regulation [12]. Conversely, a 20-year cohort study in China showed that the cumulative incidence of prediabetes was $>90 \%$ when no intervention was provided [13].

Many studies have proposed and conducted behavioral interventions for individuals with prediabetes, and some positive results have been obtained in China. However, few studies have focused on rural elderly adults with prediabetes. A national survey has confirmed that the prevalence of prediabetes in rural China is significantly higher than that in urban areas and is rising rapidly [14]. The Chinese Diabetes Society (CDS) also demonstrated that old age plays an important role in this process and called for lifestyle interventions to prevent the development of prediabetes [15]. Considering the large number of elderly adults in rural China and the rapid growth of prediabetes, we conducted this study to explore potential unhealthy lifestyle behaviors among rural elderly adults with prediabetes and to analyze the clustering of these behaviors and their influencing factors. Our ultimate goal was to provide a basis for preventing diabetes by intervening in risk factors that lead to the clustering of unhealthy lifestyle behaviors.

\section{METHODS}

\section{Participants}

This study was conducted in Yiyang City, Hunan Province, China, from April to July 2015. We calculated the sample size according to the formula for cross-sectional sampling: $\mathrm{n}=u_{\alpha / 2}^{2} P(1-P) / \delta^{2}$, where $\alpha$ was $0.05, P$ was $20 \%$ of the prediabetes prevalence (according to previously reported studies), and $\delta$ was $0.2 P$ of the admissible error. Based on these known variables, we inferred a sample size of 384 . Assuming that some subjects would drop out halfway, we increased the sample size by $10 \%$, and the final theoretical sample size was 423 . 
Through a multistage cluster random sampling design, we enrolled residents aged 60 years and above in 2 counties or districts, 4 towns and 42 villages. The detailed sampling process was previously reported [16] (Figure S1). A total of 2144 elderly adults were selected to undergo an oral glucose tolerance test (OGTT).

During the implementation of the OGTT, the subjects consumed $300 \mathrm{ml}$ of water containing $75 \mathrm{~g}$ of anhydrous glucose orally between 7 a.m. and 9 a.m. on an empty stomach (fasting time was 8-10 h). The participants were told to drink the glucose solution in $5 \mathrm{~min}$. The time was calculated starting at the first drink of the glucose solution, and blood glucose values were measured $2 \mathrm{~h}$ before and after consumption using samples taken from the forearm. The participants were asked to maintain their usual physical activity and diet at least 3 days before the OGTT. The criteria for prediabetes diagnosis were based on a 1999 World Health Organization (WHO) definition [1]: (1) IFG (fasting blood glucose values between 6.1 and $7.0 \mathrm{mmol} / \mathrm{l}$ and a 2-h post-glucose load $<7.8 \mathrm{mmol} / \mathrm{l}$ ); (2) IGT (fasting blood glucose $\leq 6.1 \mathrm{mmol} / \mathrm{l}$ and a 2 -h post glucose load of $7.8-11.1 \mathrm{mmol} / \mathrm{l}$ ); (3) IFG and IGT. If the subjects were prediabetic and were local residents aged 60 years or older, they were included in further surveys and anthropometric measurements. Subjects were excluded if they were already diabetic or had a severe physical illness.

\section{Demographic Information}

Demographic information included age, gender, education, marital status, personal annual income, occupation, family history of diabetes, hyperglycemia history and chronic medical history. Family history was defined as the presence of diabetic patients among three generations of relatives with blood relationships. Hyperglycemia history included blood glucose levels above normal that did not meet the diagnostic criteria for diabetes. Chronic diseases included hypertension, hyperlipidemia and coronary heart disease that were clearly diagnosed by doctors.

\section{Anthropometric Measurements}

Anthropometric measurements included height, weight, waist circumference, hip circumference, blood pressure and blood fat. Weight was measured by an electronic scale accurate to $0.1 \mathrm{~kg}$. Height was assessed after the subjects took off their shoes using an instrument with a maximum measurement range of $2.0 \mathrm{~m}$ and an accuracy of $0.1 \mathrm{~cm}$. Waist circumference measured the horizontal circumference from the lowest costal lower margin to the midpoint of the iliac crest line at the end of exhalation. Hip circumference was the horizontal circumference measured by a tape measure at the maximum extension of the subject's hips. We calculated body mass index (BMI) based on height and weight $\left(\mathrm{BMI}=\mathrm{kg} / \mathrm{m}^{2}\right)$ and calculated the waist-to-hip ratio (WHR) based on waist circumference and hip circumference (waist/hip circumference). According to the Chinese BMI standard for adults [17], subjects were defined as lean (BMI $<18.5)$, normal $(18.5<\mathrm{BMI}<24.0)$, overweight $(24.0<\mathrm{BMI}$ $<28.0$ ) and obese (BMI $\geq 28.0)$. The WHR was defined as abnormal when WHR $>0.9$ in men and WHR $>0.8$ in women. Blood pressure was measured using an electronic sphygmomanometer three times ( 2 min apart) after a quiet 5-min break, and the average was taken as the final blood pressure. Hypertension was defined as systolic pressure consistently $>18.6 \mathrm{kPa}$ or a consistent diastolic pressure of $12 \mathrm{kPa}$ or more. Blood lipids were measured using enzyme analysis of serum samples taken between 7:00 a.m. and 9:00 a.m. According to the guidelines on the prevention and treatment of dyslipidemia in Chinese adults (2007 edition) [18], hyperlipidemia was defined as total cholesterol $(\mathrm{TC}) \geq 6.22 \mathrm{mmol} / \mathrm{l}$ or triglyceride (TG) $\geq 2.26 \mathrm{mmol} / \mathrm{l}$.

\section{Unhealthy Lifestyle Behaviors}

Unhealthy lifestyles included five categories in the current study (unreasonable diet, lack of physical activity, smoking, excessive drinking and low diabetes health literacy). 


\section{Diet}

The Questionnaire of the Chinese Nutrition and Health Surveillance 2010 (CNHS2010) was used to measure the food intake of the subjects [19]. We asked the participants about the frequency with which they consumed each type of food in the past year and the average amount of food consumed each time. The dietary quality of the subjects was evaluated using the revised Diet Balance Index 2007 (DBI-07). According to the DBI-07 index value and scoring method, in the absence of drinking data, $1-14$ points was defined as an appropriate diet, 15-29 points indicated a low level of dietary imbalance, 30-43 was classified as a moderate imbalance, and 43-72 was classified as a severe imbalance. In this study, low, moderate and severe dietary imbalances were defined as unreasonable diets, and appropriate diets were defined as reasonable diets.

\section{Physical Activity}

The International Physical Activity Questionnaire (IPAQ-Long version) was used to investigate the type, intensity and duration of physical activity the participants engaged in and their metabolic equivalents (METs) over the past week [20]. According to the physical activity attributes indicated on the questionnaire, the participants' individual physical activity level grouping and the MET value, the subjects were given an accurate physical activity rating (Table S1). In this study, low-level physical activity was defined as a lack of physical activity. Moderate- or high-level physical activity was defined as adequate physical activity.

\section{Smoking and Drinking}

The smoking and drinking status of the rural elderly participants was investigated by a selfdesigned questionnaire. According to the definition of smoking in the third Chinese health service survey in 2003, we defined a smoker as a person who has smoked continuously or accumulatively for $>6$ months and smokes at least one cigarette per day [21]. According to the Chinese dietary guidelines, it is appropriate for males to drink $\leq 25 \mathrm{~g} /$ day and for females to drink $\leq 15 \mathrm{~g} /$ day. Amounts in excess of these recommendations were considered excessive drinking [22].

\section{Diabetes Health Literacy}

Diabetes health literacy refers to an individual's ability to access, understand and make appropriate decisions to access basic health information and services [23]. It is not a lifestyle behavior but is reflected in an individual's daily lifestyle behaviors, and it is directly related to the health outcomes of people with diabetes. Therefore, we explored it along with lifestyle behaviors. The diabetes health literacy of the participants was measured using the Questionnaire of Chinese Public Diabetes Health Literacy, which has high reliability and validity, with a Cronbach's $\alpha$ of 0.866 . The questionnaire is divided into three dimensions: basic knowledge of diabetes, behaviors related to diabetes prevention and acquisition and utilization of diabetes information. For the basic knowledge dimension (dimension 1), participants receive 1 point for correct answers and 0 point for incorrect answers. For dimension 2 and dimension 3, subjects receive 2 points if they engage in all the behaviors, 1 point if they engage in some of the behaviors and 0 points if they do not engage in any of the behaviors. The sum of the scores on the three dimensions is the total diabetes health literacy score. A score $\geq$ $60 \%$ is considered high diabetes health literacy [24].

\section{Statistical Analysis}

Data on demographic information and the unhealthy lifestyle clustering status are presented as the mean \pm SD and percentage. The Kruskal-Wallis test was used to analyze the differences in unhealthy lifestyle clustering by demographic characteristics. The factors influencing unhealthy lifestyle clustering in the prediabetic elderly participants were analyzed by ordinal logistic regression. All analyses were performed using SPSS 20.0 (SPSS/IBM, Armonk, NY, USA). Bilateral tests were used for all analyses, and a $P$ value $<0.05$ was considered statistically significant. 
The study was approved by the Medical Ethics Committee of Central South University (Changsha, China; identification code: CTXY150002-7; 27 February, 2015). The study was conducted according to the Helsinki declaration, and the study has obtained informed consent from participants.

\section{RESULTS}

\section{Sample Characteristics}

A total of 461 elderly adults were screened for prediabetes and participated in face-to-face interviews, and 425 of them completed the questionnaire (30 had no responses, and 6 had incomplete data). As shown in Table 1, 180 (42.4\%) males and 245 (57.6\%) females were interviewed. A total of $232(54.6 \%)$ participants were between 60 and 69 years old, accounting for the largest proportion of all age groups. A total of 344 (80.9\%) subjects had only a primary or lower educational background, 117 (27.5\%) people had an unstable marital status, 226 (53.2\%) patients had a normal BMI, $36(8.5 \%)$ patients had a family history of diabetes, and 27 had a history of hyperglycemia. In total, 194 (45.6\%), $122(28.7 \%)$ and $51(12.0 \%)$ of the elderly participants had hypertension, hyperlipidemia and coronary heart disease, respectively.

\section{Unhealthy Lifestyles and their Clustering} among Rural Elderly Adults with Prediabetes In this study, among the five categories, 198 (46.6\%) elderly adults had unreasonable diets; $103(24.2 \%)$ had insufficient physical activity; 130 (30.4\%) and 93 (21.9\%) individuals smoked and drank excessively, respectively; 412 (96.9\%) had a state of low diabetes health literacy. A total of $325(76.47 \%)$ elderly patients had unhealthy lifestyle clustering; of these, 144 (33.9\%) had 1 unhealthy lifestyle behavior, 116 (27.3\%) had 2 unhealthy lifestyle behaviors, 52 (12.2\%) had 3 unhealthy lifestyle behaviors, and $13(3.0 \%)$ had 4 or more unhealthy lifestyle behaviors (Table 2).
Table 1 Characteristics of the study sample $(N=425)$

\begin{tabular}{|c|c|c|}
\hline Variable & Frequency & $\begin{array}{l}\text { Mean } \pm \text { SD } / \\
\text { prevalence }(\%)\end{array}$ \\
\hline Age, years & 425 & $69.5 \pm 6.48$ \\
\hline \multicolumn{3}{|l|}{ Gender } \\
\hline Male & 180 & 42.4 \\
\hline Female & 245 & 57.6 \\
\hline \multicolumn{3}{|l|}{ Education } \\
\hline Primary school and below & 344 & 80.9 \\
\hline $\begin{array}{l}\text { Junior high school and } \\
\text { above }\end{array}$ & 81 & 19.1 \\
\hline \multicolumn{3}{|l|}{ Marital status } \\
\hline Stable & 308 & 72.5 \\
\hline Unstable $^{\mathrm{a}}$ & 117 & 27.5 \\
\hline \multicolumn{3}{|l|}{$\begin{array}{l}\text { Personal annual income } \\
\quad(\mathrm{CNY})\end{array}$} \\
\hline $0-2800$ & 89 & 20.9 \\
\hline$\geq 2800$ & 336 & 79.1 \\
\hline \multicolumn{3}{|l|}{ Occupation } \\
\hline Farmer & 194 & 45.6 \\
\hline Worker & 98 & 23.1 \\
\hline Retired staff & 69 & 16.2 \\
\hline Others ${ }^{\mathrm{b}}$ & 64 & 15.1 \\
\hline \multicolumn{3}{|l|}{ BMI } \\
\hline Lean & 17 & 4.0 \\
\hline Normal & 226 & 53.2 \\
\hline Overweight & 128 & 30.1 \\
\hline Obese & 54 & 12.7 \\
\hline \multicolumn{3}{|l|}{ WHR } \\
\hline High & 355 & 83.5 \\
\hline Normal & 70 & 16.5 \\
\hline \multicolumn{3}{|l|}{ Family history of diabetes } \\
\hline Yes & 36 & 8.5 \\
\hline \multicolumn{3}{|l|}{ History of hyperglycemia } \\
\hline Yes & 27 & 6.4 \\
\hline
\end{tabular}


Table 1 continued

\begin{tabular}{|c|c|c|}
\hline Variable & Frequency & $\begin{array}{l}\text { Mean } \pm \mathrm{SD} / \\
\text { prevalence }(\%)\end{array}$ \\
\hline \multicolumn{3}{|c|}{ Hypertension } \\
\hline Yes & 194 & 45.6 \\
\hline \multicolumn{3}{|c|}{ Hyperlipidemia } \\
\hline Yes & 122 & 28.7 \\
\hline \multicolumn{3}{|c|}{ Coronary heart disease } \\
\hline Yes & 51 & 12.0 \\
\hline \multicolumn{3}{|c|}{$\begin{array}{l}C N Y \text { Chinese yuan, } B M I \text { body mass index, } W H R \text { waist-to- } \\
\text { hip ratio } \\
\text { a Unstable marital status includes unmarried, divorced, } \\
\text { widowed, etc. } \\
\text { b Others include self-employed, unemployed, etc. }\end{array}$} \\
\hline
\end{tabular}

Comparison of Clusters of Unhealthy Lifestyle Behaviors among Different Participants

The Kruskal-Wallis test was performed by classifying the number of unhealthy lifestyle clusters as $0,1-2$ and $\geq 3$ and using cluster as a dependent variable with the participants' characteristics as independent variables (Table S2). The results showed a statistically significant difference in unhealthy lifestyle clustering by age, gender, marital status, occupation and hyperlipidemia $(P<0.05)$. Conversely, no significant difference in unhealthy lifestyle clustering was found among participants with differences in educational background, personal annual income, diabetes health literacy, BMI, WHR, family history of diabetes and chronic medical history $(P>0.05)$ (Table 3$)$.

\section{Factors Influencing Unhealthy Lifestyle Clustering in Rural Elderly People with Prediabetes}

A multivariate ordinal logistic regression analysis was conducted to investigate the independent factors that influenced unhealthy lifestyle clustering in prediabetic elderly adults with different characteristics, and the logit function was adopted as the link function. The model fit information test showed that the ordinal regression model was meaningful $\left(\chi^{2}=346.057\right.$, $P<0.001)$, and the goodness-of-fit test
Table 2 Unhealthy lifestyles and their clustering among the participants $(N=425)$

\begin{tabular}{|c|c|c|}
\hline Variables & Frequency & $\begin{array}{l}\text { Prevalence } \\
(\%)\end{array}$ \\
\hline \multicolumn{3}{|l|}{ Dietary quality } \\
\hline Reasonable diet & 227 & 53.4 \\
\hline Unreasonable diet & 198 & 46.6 \\
\hline \multicolumn{3}{|l|}{ Physical activity } \\
\hline Sufficient & 322 & 75.8 \\
\hline Insufficient & 103 & 24.2 \\
\hline \multicolumn{3}{|l|}{ Smoking } \\
\hline Yes & 130 & 30.6 \\
\hline No & 295 & 69.4 \\
\hline \multicolumn{3}{|l|}{ Excessive drinking } \\
\hline Yes & 93 & 21.9 \\
\hline No & 332 & 78.1 \\
\hline \multicolumn{3}{|l|}{ Diabetes health literacy } \\
\hline Low diabetes health literacy & 412 & 96.9 \\
\hline High diabetes health literacy & 13 & 3.1 \\
\hline \multicolumn{3}{|l|}{$\begin{array}{l}\text { Number of unhealthy lifestyles } \\
\text { clusters }\end{array}$} \\
\hline 1 & 144 & 33.9 \\
\hline 2 & 116 & 27.3 \\
\hline 3 & 52 & 12.2 \\
\hline$\geq 4$ & 13 & 3.0 \\
\hline
\end{tabular}

indicated that the model fit well (Pearson's test, $P=0.134)$. The parallel line test value was $\chi^{2}=8.621$ and $P=0.374$, indicating that the parallelism assumption was correct and that this study could be analyzed using ordinal logistic regression.

As shown in Table 4, after all variables were entered into the model, the independent factors influencing unhealthy lifestyle clustering were gender, marital status, personal annual income, occupation and diabetes health literacy. Being female $(\mathrm{OR}=0.23,95 \%$ CI: 0.150 .37$)$ and having an annual personal annual income 
Table 3 Kruskal-Wallis test analysis of unhealthy lifestyles clustering among different participants $(N=425)$

\begin{tabular}{|c|c|c|c|c|c|}
\hline \multirow[t]{2}{*}{ Variables } & \multicolumn{3}{|c|}{ Number of unhealthy lifestyles clusters } & \multirow[t]{2}{*}{$Z$} & \multirow[t]{2}{*}{$\boldsymbol{P}$} \\
\hline & $0(N=100)$ & $1-2(N=260)$ & $\geq 3(N=65)$ & & \\
\hline \multicolumn{6}{|l|}{ Age, years } \\
\hline $60-69$ & $63(27.2)$ & $129(55.6)$ & $40(17.2)$ & 7.78 & $0.02^{*}$ \\
\hline $70-79$ & $35(20.7)$ & $112(66.3)$ & $22(13.0)$ & & \\
\hline$\geq 80$ & $2(8.3)$ & $19(79.2)$ & $3(12.5)$ & & \\
\hline \multicolumn{6}{|l|}{ Gender } \\
\hline Male & $18(10.0)$ & $117(65.0)$ & $45(25.0)$ & -6.65 & $<0.01^{* *}$ \\
\hline Female & $82(33.5)$ & $143(58.4)$ & $20(8.2)$ & & \\
\hline \multicolumn{6}{|l|}{ Education } \\
\hline Primary school and below & $84(24.4)$ & $210(61.0)$ & $50(14.5)$ & -1.13 & 0.26 \\
\hline Junior high school and above & $16(19.8)$ & $50(61.7)$ & $15(18.5)$ & & \\
\hline \multicolumn{6}{|l|}{ Marital status } \\
\hline Stable & $81(26.3)$ & $183(59.4)$ & $44(14.3)$ & -2.08 & $0.04^{*}$ \\
\hline Unstable $^{\mathrm{a}}$ & $19(16.2)$ & $77(65.8)$ & $21(17.9)$ & & \\
\hline \multicolumn{6}{|l|}{ Personal annual income (CNY) } \\
\hline $0-2800$ & $14(15.7)$ & $60(67.4)$ & $15(16.9)$ & -1.65 & 0.99 \\
\hline$\geq 2800$ & $86(25.6)$ & $200(59.5)$ & $50(14.9)$ & & \\
\hline \multicolumn{6}{|l|}{ Occupation } \\
\hline Farmer & $38(19.6)$ & $119(61.3)$ & $37(19.1)$ & 11.09 & $0.01^{*}$ \\
\hline Worker & $30(30.6)$ & $55(56.1)$ & $13(13.3)$ & & \\
\hline Retired staff & $21(30.4)$ & $44(63.8)$ & $4(5.8)$ & & \\
\hline Others ${ }^{b}$ & $11(17.2)$ & $42(65.6)$ & $11(17.2)$ & & \\
\hline \multicolumn{6}{|l|}{ BMI } \\
\hline Lean & $6(35.3)$ & $8(47.1)$ & $3(17.6)$ & 2.57 & 0.46 \\
\hline Normal & $55(24.3)$ & $138(61.1)$ & $33(14.6)$ & & \\
\hline Overweight & $29(22.7)$ & $82(64.1)$ & $17(13.3)$ & & \\
\hline Obese & $10(18.5)$ & $32(59.3)$ & $12(22.2)$ & & \\
\hline \multicolumn{6}{|l|}{ WHR } \\
\hline High & $78(22.0)$ & $227(63.9)$ & $50(14.1)$ & -0.37 & 0.72 \\
\hline Normal & $22(31.4)$ & $33(47.1)$ & $15(21.4)$ & & \\
\hline \multicolumn{6}{|l|}{ Diabetes health literacy } \\
\hline Low diabetes health literacy & $96(23.3)$ & $253(61.4)$ & $63(15.3)$ & -0.44 & 0.69 \\
\hline High diabetes health literacy & $4(30.8)$ & $7(53.8)$ & $2(15.4)$ & & \\
\hline
\end{tabular}


Table 3 continued

\begin{tabular}{|c|c|c|c|c|c|}
\hline \multirow[t]{2}{*}{ Variables } & \multicolumn{3}{|c|}{ Number of unhealthy lifestyles clusters } & \multirow[t]{2}{*}{$Z$} & \multirow[t]{2}{*}{$P$} \\
\hline & $0(N=100)$ & $1-2(N=260)$ & $\geq 3(N=65)$ & & \\
\hline \multicolumn{6}{|c|}{ Family history of diabetes } \\
\hline Yes & $6(13.9)$ & $25(72.2)$ & $5(13.9)$ & -0.59 & 0.55 \\
\hline No & $94(25.2)$ & $235(59.4)$ & $60(15.4)$ & & \\
\hline \multicolumn{6}{|c|}{ History of hyperglycemia } \\
\hline Yes & $5(18.5)$ & $18(66.7)$ & $4(14.8)$ & -0.42 & 0.68 \\
\hline No & $95(23.9)$ & $242(60.8)$ & $61(15.3)$ & & \\
\hline \multicolumn{6}{|c|}{ Hypertension } \\
\hline Yes & $44(22.7)$ & $114(58.8)$ & $36(18.6)$ & -1.21 & 0.23 \\
\hline No & $56(24.2)$ & $146(63.2)$ & $29(12.6)$ & & \\
\hline \multicolumn{6}{|c|}{ Hyperlipidemia } \\
\hline Yes & $10(8.2)$ & $91(74.6)$ & $21(17.2)$ & -3.77 & $<0.01^{* *}$ \\
\hline No & $90(29.7)$ & $169(55.8)$ & $44(14.5)$ & & \\
\hline \multicolumn{6}{|c|}{ Coronary heart disease } \\
\hline Yes & $8(15.7)$ & $38(74.5)$ & $5(9.8)$ & -0.37 & 0.71 \\
\hline No & $92(24.6)$ & $222(59.4)$ & $60(16.0)$ & & \\
\hline
\end{tabular}

$C N Y$ Chinese yuan, BMI body mass index, WHR waist-to-hip ratio

${ }^{*} P<0.05,{ }^{* *} P<0.01$

${ }^{a}$ Unstable marital status includes unmarried, divorced, widowed, etc. ${ }^{\text {b }}$ Others include self-employed, unemployed, etc.

$\geq 2800 \mathrm{CNY}$ (OR $=0.61,95 \% \mathrm{CI}: 0.380 .99)$ and an occupation as a worker $(\mathrm{OR}=0.56,95 \% \mathrm{CI}$ : $0.34 \quad 0.92$ ) were protective factors against unhealthy lifestyle clustering. An unstable marital status (OR $=1.60,95 \% \mathrm{CI}: 1.02$ 2.51) and low diabetes health literacy $(\mathrm{OR}=3.17,95 \% \mathrm{CI}$ : 1.03 9.81) were risk factors.

\section{DISCUSSION}

This study is the first to explore the current status and influencing factors of unhealthy lifestyle clustering in rural elderly adults with prediabetes in China. In this study, we found significant clustering of unhealthy lifestyles among the elderly participants with prediabetes; this clustering was more obvious among the elders aged between 60 and 69 years. As age increases, the number of unhealthy lifestyle clusters decreases. Two reasons may explain this finding. First, this age group has a large population base and tends to have a strong degree of independence. In addition to physical inactivity, other unhealthy lifestyles occurred frequently. Second, as most studies have stated, older people are more likely to be diagnosed with diabetes. Degenerative changes in the elderly, such as decreased islet function and impaired glucose metabolism, may trigger diabetes $[25,26]$. Fat deposits in elderly adults are also prone to insulin resistance [27]. Once diagnosed, these elderly individuals are more likely to follow doctors' advice and control their unhealthy habits, thereby reducing their number of unhealthy lifestyle behaviors. 
Table 4 Independent influential factors for unhealthy lifestyle clustering in the participants

\begin{tabular}{|c|c|c|c|c|c|c|c|}
\hline Variables & $b$ & $S E$ & Wald $\chi^{2}$ & $P$ & $O R$ & $95 \% C$ & \\
\hline \multicolumn{8}{|l|}{ Gender } \\
\hline Female & -1.453 & 0.238 & 37.413 & $<0.01^{* *}$ & 0.23 & 0.15 & 0.37 \\
\hline Male & & & & & 1.00 & & \\
\hline \multicolumn{8}{|l|}{ Marital status } \\
\hline Unstable $^{\mathrm{a}}$ & 0.469 & 0.229 & 4.179 & $0.04^{*}$ & 1.60 & 1.02 & 2.51 \\
\hline Stable & & & & & 1.00 & & \\
\hline \multicolumn{8}{|l|}{ Personal annual income (CNY) } \\
\hline$\geq 2800$ & -0.494 & 0.248 & 3.965 & $0.04^{*}$ & 0.61 & 0.38 & 0.99 \\
\hline$<2800$ & & & & & 1.00 & & \\
\hline \multicolumn{8}{|l|}{ Occupation } \\
\hline Worker & -0.587 & 0.259 & 5.160 & $0.02^{*}$ & 0.56 & 0.34 & 0.92 \\
\hline Retired staff & -0.404 & 0.307 & 1.731 & 0.19 & 0.67 & 0.37 & 1.22 \\
\hline Others $^{b}$ & 0.215 & 0.302 & 0.506 & 0.48 & 1.24 & 0.69 & 2.24 \\
\hline Farmer & & & & & 1.00 & & \\
\hline \multicolumn{8}{|l|}{ Diabetes health literacy } \\
\hline Low diabetes health literacy & 1.155 & 0.575 & 2.010 & $0.04^{*}$ & 3.17 & 1.03 & 9.81 \\
\hline High diabetes health literacy & & & & & 1.00 & & \\
\hline
\end{tabular}

$C N Y$ Chinese yuan, $O R$ odds ratio, $C I$ confidence interval ${ }^{*} P<0.05,{ }^{* *} P<0.01$

${ }^{a}$ Unstable marital status includes unmarried, divorced, widowed, etc.

b Others include self-employed, unemployed, etc.

According to our findings, the proportion of unhealthy lifestyle clustering in elderly adults with hyperlipidemia was significantly higher than that in participants without hyperlipidemia. As an independent disease, hyperlipidemia is associated with many unhealthy lifestyle factors, such as high-fat diet, smoking, alcohol use and lack of exercise, which are also risk factors for diabetes [28, 29]. Epidemiologic studies have shown that a high-fat diet is an important risk factor for hyperlipidemia as well as a direct factor mediating the development of hyperlipidemia into diabetes. For example, by inducing transforming growth factor- $\beta$ (TGF- $\beta$ ) signaling to trigger insulin resistance and increasing the expression of the protein kinase negative regulator tribbles, a high-fat diet directly increases the risk of diabetes [30]. Furthermore, people with hyperlipidemia decompose large amounts of free fatty acids, which stimulates related substances, triggers oxidative stress, and destroys DNA and molecules, all of which are closely related to insulin resistance and the emergence of diabetes [31].

In our screening, the proportion of women without unhealthy lifestyle clustering was approximately four times that of men, and male gender was confirmed as an independent risk factor for unhealthy lifestyle clustering. In traditional Chinese culture, men are usually under more pressure than women and are more likely to develop unhealthy lifestyles because they are responsible for the household's main economic expenditures [32]. Previous evidence also shows 
that women are far less likely to smoke and drink alcohol than men. In 2011, for example, $61 \%$ of Chinese men smoked compared with $4.2 \%$ of Chinese women [33]. A diabetes prevention trial found that less than a third of men were willing to take part in such trials, but the effects of the trial were the same for both men and women [34], similar to the results for other weight loss trials [35]. This finding suggests that future interventions need to focus more on engaging men.

Clearly, the clustering of unhealthy lifestyle behaviors in participants with unstable marriages was higher than that of participants with stable marriages. Previous studies demonstrated that marriage affects a spouse's quality of life primarily through diet and lifestyle [36]. Due to the large number of widowers among elderly adults and the small proportion who remarry, marital instability may affect their normal living habits. This result is consistent with the findings of Martin et al., who reported that widowers showed a higher prevalence of diabetes than married people [37]. Additionally, in rural China, the number of empty-nest elderly adults is increasing rapidly. These people have long experienced different levels of loneliness and depression because their children have not been around for a long time [38]. An unstable marital status will aggravate mental stress in these elderly adults and affect their quality of life. When an unhealthy lifestyle behavior emerges, it will gradually deteriorate because of a lack of supervision from family members.

In this study, we confirmed that a higher personal annual income was a protective factor against unhealthy lifestyle clustering, whereas an occupation as a farmer was a risk factor. Income and occupation can collectively reflect the socioeconomic status of the subject. Socioeconomic inequalities in health and risk factors are well known, as is Hart's inverse care law, which states that those with the highest need are the least likely to receive health care [39]. Mokdad et al. had similar findings; they found that people with a lower socioeconomic status had a higher risk of developing diabetes [40]. People with low socioeconomic levels tend to have poor living conditions and unreasonable diets and are more likely to develop impaired glucose tolerance and type 2 diabetes than the general population. In rural China, farmers generally have no stable income, and their overall education level is very low. They do not have sufficient diabetes health literacy and lack effective access to comprehensive information for diabetes prevention. Conversely, retired staff represent those with higher education levels and a steady income, and thus they comprise the smallest proportion of those with unhealthy lifestyle clustering in this study. These people tend to have more time and money to adjust their lifestyle, and they are more concerned about their health.

Incredibly, $96.9 \%$ of subjects showed low levels of diabetes health literacy, which has been proven to be an independent risk factor for unhealthy lifestyle clustering in rural elderly adults. Elderly people with low diabetes health literacy tend to have difficulties not only with reading medication instructions and checklists but also with oral communication with doctors and risk assessment. They usually show low compliance with medication, follow-up and diabetes management and may even present a variety of unhealthy lifestyle behaviors. Schillinger et al. found that patients with low health literacy had worse levels of glycemic control and a greater chance of developing retinopathy [41]. Pulgaron et al. reported that improving the health literacy of parents with type 1 diabetes was significant for reducing the blood glucose levels of their children [42]. Considering that diabetes health literacy directly affects the health outcomes of diabetic individuals, the American Diabetes Association (ADA) has made improving health literacy in patients with diabetes an important part of the overall treatment plan for diabetes [41, 43]. Admittedly, a low educational background has been reported to be a major risk factor for a low level of diabetes health literacy [44]. Men show lower diabetes health literacy than women because they are reluctant to pay more attention to preventative health care [16]. Therefore, improving the health literacy of elderly men and those with less education is essential for prediabetes prevention in rural elderly adults.

To our knowledge, basic lifestyle interventions for prediabetic individuals can produce 
significant effects. However, most studies have targeted only one or two behaviors [45, 46]. Comprehensive lifestyle interventions are clearly more desired, but insufficient epidemiologic information is available on the cost-effectiveness of comprehensive interventions. We believe that large-scale interventions and sustained outreach for prediabetic elderly adults will require considerable resources and will have difficulty achieving significant results in the short term. Our research may provide public health decision makers and community service workers with recommendations to help them focus limited resources on interventions targeting risk factors for unhealthy lifestyle clustering in elderly adults with prediabetes. Our findings will also be useful to clinical practitioners when these prediabetic elderly adults are hospitalized. Our random sample in this study was representative, and the results can be generalized to other rural areas in China. The specific findings of this study may or may not hold true in other countries where demographic characteristics and cultural backgrounds are different.

There are three limitations to this study. First, this study had a cross-sectional design; therefore, we cannot infer a causal relationship. Second, the measurement tools used were mainly targeted toward Chinese people, and our outcomes may be more representative of China's rural elderly adults and not conducive to generalization. Finally, we cannot deny the bias introduced by the self-reported design, and underreporting of unhealthy lifestyles would contribute to more conservative findings.

\section{CONCLUSION}

This study showed a high prevalence of unhealthy lifestyle clustering among elderly people with prediabetes in rural China. Being female and having a stable marital status and a personal annual income $\geq 2800 \mathrm{CNY}$ are protective factors against unhealthy lifestyle clustering, whereas being a farmer and having low diabetes health literacy are risk factors. Considering the large number and rapid growth of prediabetic elderly adults in rural China, the current study underlines the need for further intervention among rural prediabetic elderly adults with a focus on these influencing factors.

\section{ACKNOWLEDGEMENTS}

We thank Zhao Hu, Yang Yang, Ting Zhang and Fangfan Jiang for their assistance as investigators in this study and all the participants for their cooperation.

Funding. No funding or sponsorship was received for this study. The Rapid Service Fee was funded by the authors.

Authorship. All named authors meet the International Committee of Medical Journal Editors (ICMJE) criteria for authorship for this article, take responsibility for the integrity of the work as a whole, and have given their approval for this version to be published.

Author Contributions. Conceptualization: HLX; methodology: HLX and XFW; software: HLG; writing-original draft preparation: XFW; review \& editing: HLX; supervision: HLX.

Disclosures. Xiaofen Wang, Hailiang Gao and Huilan $\mathrm{Xu}$ have nothing to disclose.

Compliance with Ethics Guidelines. The study was approved by the Medical Ethics Committee of Central South University (Changsha, China; identification code: CTXY150002-7; 27 February, 2015). The study was conducted according to the Helsinki declaration, and the study has obtained informed consent from participants.

Data Availability. The datasets used during and/or analyzed during the current study are available from the corresponding author on reasonable request.

Open Access. This article is distributed under the terms of the Creative Commons Attribution-NonCommercial 4.0 International License (http://creativecommons.org/licenses/ by-nc/4.0/), which permits any 
noncommercial use, distribution, and reproduction in any medium, provided you give appropriate credit to the original author(s) and the source, provide a link to the Creative Commons license, and indicate if changes were made.

\section{REFERENCES}

1. Department of noncommunicable disease surveillance. Definition, diagnosis and classification of diabetes mellitus and its complications: report of a WHO consultation. Part 1. Diagnosis and classification of diabetes mellitus. Geneva: World Health Organization; 1999.

2. Centers for disease control and prevention. National diabetes statistics report: estimates of diabetes and its burden in the United States. Department of health and human services. 2014;1:1-8.

3. Yang W, Lu J, Weng J, Jia W, Ji L, Xiao J, Shan Z, Liu J, Tian H, Ji Q, et al. Prevalence of diabetes among men and women in China. New England J Med. 2010;362(12):1090-101.

4. International diabetes federation. IDF Diabetes Atlas. 7th ed. Belgium: International Diabetes Federation. Brussels; 2015.

5. Owei I, Umekwe N, Mohamed H, Ebenibo S, Wan J, Dagogo-Jack S. Ethnic disparities in endothelial function and its cardiometabolic correlates: the pathobiology of prediabetes in a biracial cohort study. Front Endocrinol. 2018;9:94.

6. Reis JP, Allen NB, Bancks MP, Carr JJ, Lewis CE, Lima JA, Rana JS, Gidding SS, Schreiner PJ. Duration of diabetes and prediabetes during adulthood and subclinical atherosclerosis and cardiac dysfunction in middle age: the cardia study. Diabetes Care. 2018;41(4):731-8.

7. Stacey RB, Leaverton PE, Schocken DD, Peregoy JA, Bertoni AG. Prediabetes and the association with unrecognized myocardial infarction in the multiethnic study of atherosclerosis. Am Heart J. 2015;170(5):923-8.

8. Wei XB, Liu YH, Huang JL, Chen XL, Yu DQ, Tan N, Chen JY, He PC. Prediabetes and diabetes are both risk factors for adverse outcomes in infective endocarditis. Diabetic Med. 2018;35(11):1499-507.

9. The diabetes prevention program: baseline characteristics of the randomized cohort. The diabetes prevention program research group. Diabetes Care. 2000;23(11):1619-29.

10. Christensen P, Meinert Larsen T, Westerterp-Plantenga M, Macdonald I, Martinez JA, Handjiev S, Poppitt S, Hansen S, Ritz C, Astrup A, et al. Men and women respond differently to rapid weight loss: Metabolic outcomes of a multi-centre intervention study after a low-energy diet in 2500 overweight, individuals with pre-diabetes (PREVIEW). Diabetes Obes Metabol. 2018;20(12):2840-51.

11. DeJesus RS, Clark MM, Finney Rutten LJ, Jacobson RM, Croghan IT, Wilson PM, Jacobson DJ, Link SM, Fan C, St Sauver JL. Impact of a 12-week wellness coaching on self-care behaviors among primary care adult patients with prediabetes. Prev Med Rep. 2018;10:100-5.

12. Stefan N, Staiger H, Wagner R, Machann J, Schick F, Haring HU, Fritsche A. A high-risk phenotype associates with reduced improvement in glycaemia during a lifestyle intervention in prediabetes. Diabetologia. 2015;58(12):2877-84.

13. Wang J, Zhang B, Jiang Y, Shuai Y, Yali AN, Hui LI, Chunqin LI, Wang Y, Gong Q, Zhang J. Improving glucose intolerance linked with the reduction of cardiovascular disease events and mortality in a Da Qing population with pre-diabetes-a 20 year follow-up study. Chin J Endocrinol Metab. 2010;26(1):6-9.

14. Yang SH, Dou KF, Song WJ. Prevalence of diabetes among men and women in China. New England J Med. 2010;362(25):2425-6.

15. CD Society. Chinese guidelines for the prevention and treatment of type 2 diabetes. Chin J Endocrinol Metab. 2014;6:447-98.

16. Qin $\mathrm{L}, \mathrm{Xu} \mathrm{H}$. A cross-sectional study of the effect of health literacy on diabetes prevention and control among elderly individuals with prediabetes in rural China. BMJ open. 2016;6(5):e011077.

17. Wu Y. Overweight and obesity in China. BMJ. 2006;333(7564):362-3.

18. Chinese guidelines for prevention and treatment of dyslipidemia in adults. Zhonghua Xin Xue Guan Bing Za Zhi. 2007;35(5):390-419 (in Chinese).

19. Liu R, Zhao Y, Yan H, Dang S, Pang S, Wang X, Wang F. Using the revised Chinese diet balance index Quality of Diet to evaluate the quality of diet among rural residents in Hanzhong, Shaanxi province and relative influencing factors. Zhonghua Liu Xing Bing Xue Za Zhi. 2014;35(10):1087-90 (in Chinese). 
20. Craig CL, Marshall AL, Sjostrom M, Bauman AE, Booth ML, Ainsworth BE, Pratt M, Ekelund U, Yngve A, Sallis JF, et al. International physical activity questionnaire: 12-country reliability and validity. Med Sci Sports Exerc. 2003;35(8):1381-95.

21. Xiao L, Yang J, Wan X, Yang G. What is the prevalence of smoking in China. Zhonghua Liu Xing Bing Xue Za Zhi. 2009;30(1):30-3 (in Chinese).

22. Yang YX, Zhao HM. Introduction to Chinese Dietary Guidelines. Nutrition. 2016;38(3):209-17.

23. Kutner ME, Greenberg E, Jin Y, Paulsen C. The health literacy of America's adults: Results from the 2003 national assessment of adult literacy (NCES 2006-483). National Cent Educ Stat. 2006;39(10):685-7.

24. Li L, Li Y, Nie X, Huang X, Shi M, Li F, Wei W. An analysis of health literacy about diabetes prevention and control and its influencing factors among the residents in six provinces in China. Zhonghua Yu Fang Yi Xue Za Zhi. 2014;48(7):561-5 (in Chinese).

25. Gong H, Pa L, Wang K, Mu H, Dong F, Ya S, Xu G, Tao N, Pan L, Wang B, et al. Prevalence of diabetes and associated factors in the Uyghur and Han population in Xinjiang, China. Int J Environ Res Pub Health. 2015;12(10):12792-802.

26. Moody A, Cowley G, Ng Fat L, Mindell JS. Social inequalities in prevalence of diagnosed and undiagnosed diabetes and impaired glucose regulation in participants in the Health Surveys for England series. BMJ Open. 2016;6(2):e010155.

27. Hiltunen L, Kivela SL, Laara E, Keinanen-Kiukaanniemi S. Progression of normal glucose tolerance to impaired glucose tolerance or diabetes in the elderly. Diabetes Res Clin Pract. 1997;35(2-3):99-106.

28. Kuwabara M, Kuwabara R, Niwa K, Hisatome I, Smits G, Roncal-Jimenez CA, MacLean PS, Yracheta JM, Ohno M, Lanaspa MA et al. Different risk for hypertension, diabetes, dyslipidemia, and hyperuricemia according to level of body mass index in japanese and american subjects. Nutrients. 2018;10(8):1000-11.

29. Deng B, Luo T, Huang Y, Shen T, Ma J. Prevalence and determinants of hyperlipidemia in moderate altitude areas of the Yunnan-Kweichow plateau in Southwestern China. High Alt Med Biol. 2012;13(1):13-21.

30. Hong SH, Kang M, Lee KS, Yu K. High fat diet-induced TGF-beta/Gbb signaling provokes insulin resistance through the tribbles expression. Scientific Reports. 2016;6:30265.

31. Zhou K, Donnelly LA, Morris AD, Franks PW, Jennison C, Palmer CN, Pearson ER. Clinical and genetic determinants of progression of type 2 diabetes: a DIRECT study. Diabetes Care. 2014;37(3):718-24.

32. Li SP, Wang PY, Zhang J, Cai L, Qi Z, Li Z, Han XY. Analysis on diabetes prevalence among adults in Chaoyang District of Beijing City and its risk factors. Chinese J Health Education. 2011;27(2):83-86.

33. WHO urges more countries to require large, graphic health warnings on tobacco packaging: the WHO report on the global tobacco epidemic, 2011 examines anti-tobacco mass-media campaigns. Central European J Pub Health. 2011;19(3):133-151.

34. Knowler WC, Barrett-Connor E, Fowler SE, Hamman RF, Lachin JM, Walker EA, Nathan DM. Reduction in the incidence of type 2 diabetes with lifestyle intervention or metformin. New England J Med. 2002;346(6):393-403.

35. Jebb SA, Ahern AL, Olson AD, Aston LM, Holzapfel C, Stoll J, Amann-Gassner U, Simpson AE, Fuller NR, Pearson S, et al. Primary care referral to a commercial provider for weight loss treatment versus standard care: a randomised controlled trial. Lancet. 2011;378(9801):1485-92.

36. Cornelis MC, Chiuve SE, Glymour MM, Chang SC, Tchetgen Tchetgen EJ, Liang L, Koenen KC, Rimm EB, Kawachi I, Kubzansky LD. Bachelors, divorcees, and widowers: does marriage protect men from type 2 diabetes? PLoS One. 2014;9(9):e106720.

37. Martin SA, Haren MT, Taylor AW, Middleton SM, Wittert GA. Chronic disease prevalence and associations in a cohort of Australian men: the Florey Adelaide Male Ageing Study (FAMAS). BMC Pub Health. 2008;8:261.

38. Wang G, Hu M, Xiao SY, Zhou L. Loneliness and depression among rural empty-nest elderly adults in Liuyang, China: a cross-sectional study. BMJ Open. 2017;7(10):e016091.

39. Hart JT. The inverse care law. Lancet. 1971;1(7696):405-12.

40. Mokdad AH, Ford ES, Bowman BA, DE Nelson, Engelgau MM, Vinicor F, Marks JS. Diabetes trends in the U.S.: 1990-1998. Diabetes Care. 2000;23(9):1278-83.

41. Schillinger D, Grumbach K, Piette J, Wang F, Osmond D, Daher C, Palacios J, Sullivan GD, 
Bindman AB. Association of health literacy with diabetes outcomes. JAMA. 2002;288(4):475-82.

42. Pulgaron ER, Sanders LM, Patino-Fernandez AM, Wile D, Sanchez J, Rothman RL, Delamater AM. Glycemic control in young children with diabetes: the role of parental health literacy. Patient Educ Couns. 2014;94(1):67-70.

43. Executive summary: Standards of medical care in diabetes-2014. Diabetes care. 2014;37 Suppl 1:S5-13.

44. Hollman G, Olsson AG, Ek AC. Disease knowledge and adherence to treatment in patients with familial hypercholesterolemia. J Cardiovasc Nurs. 2006;21(2):103-8.
45. Rehackova L, Araujo-Soares V, Steven S, Adamson AJ, Taylor R, Sniehotta FF. Behaviour change during dietary Type 2 diabetes remission: a longitudinal qualitative evaluation of an intervention using a very low energy diet. Diabetic Med J British Diabetic Association. 2019.

46. Garcia-Ulloa AC, Landa-Anell V, Melgarejo-Hernandez M, Villegas-Narvaez A, Urbina-Arronte LE, Hernandez-Jimenez S. Assessment of a multidisciplinary intervention in patients with $\mathrm{BMI}>$ / $=35 \mathrm{~kg} / \mathrm{m} 2$ and recently diagnosed type 2 diabetes. J Clin Endocrinol Metab. 2019;104(7):2994-3002. 